\title{
The influence of ligand structure of ruthenium nitrosyl complexes on their biological activity
}

\author{
Darya Khantakova \\ ICBFM SB RAS, Novosibirsk, Russia \\ Novosibirsk State University, Novosibirsk, Russia \\ d.khantakova@alumni.nsu.ru
}

\author{
Inga Grin \\ ICBFM SB RAS, Novosibirsk, Russia \\ Novosibirsk State University, Novosibirsk, Russia \\ grin@niboch.nsu.ru
}

\begin{abstract}
The study is focused on the novel photoactive ruthenium nitrosyl complex. In previous studies, we identified new pyrimidine complex that showed the best profile of cytotoxicity. We compared the effect of chemical nature and structure of different ligands on the cytotoxic potential of complexes.
\end{abstract} repair

Keywords - ruthenium nitrosyl complex, nitric oxide, DNA

\section{Motivation and Aim}

Metal-based anticancer drugs have been used successfully in clinical therapy worldwide. The success of platinum compounds (such as cisplatin, carboplatin and oxaliplatin) in chemotherapy is undeniable. However, there are still many limitations, such as high mutagenic potential and cytotoxic activity against normal cells, resistance to the treatment of certain types of tumors. An active search for solutions to these problems has revealed a new class of compounds - ruthenium complexes $\left(\mathrm{L}_{6} \mathrm{Ru}, \mathrm{L}=\right.$ ligand $)$. They have several major advantages: ability to affect many types of cancer, lower toxicity and effectiveness against platinum-resistant types of cancer. Moreover, ruthenium complexes have shown selective biological activity as they can be administered as prodrugs and later activated within the reducing microenvironment of tumor. It is known that the radical intermediate particle $\mathrm{L}_{5} \mathrm{Ru} \cdot$ selectively accumulates in cancer tumors along through transferrin-dependent pathway, leading to the appearance of reactive oxygen species (ROS), DNA damage and initiation of apoptosis mechanisms. The oxidative damages of DNA bases could be repaired by one the most common DNA repair pathway - base excision repair (BER) initiated by specific enzymes - DNA glycosylases and it maintains the stability of the genome in healthy cells, but accelerates the tolerance to anticancer therapy. However, the molecular mechanism of action of ruthenium complexes remains unclear. On the other hand, the ligands in ruthenium complex can significantly change the effect. Nitroso-ruthenium complexes are particularly attractive candidates because of their ability to release active radicals $\mathrm{NO} \bullet$ and $\mathrm{L}_{5} \mathrm{Ru} \bullet$ through photoactivation in vitro or redox reactions in cells. In previous studies, we demonstrated possibility of using novel nitroso-ruthenium complex $\left[\mathrm{Ru}(\mathrm{NO})(\mathrm{bPic})_{2}\left(\mathrm{NO}_{2}\right)_{2} \mathrm{OH}\right] \quad(\{\mathrm{RuNO}\})$ for investigation of the inhibition effect on DNA-glycosylases in vitro [1] and measurement the cytotoxicity potential in vivo [2]. This project aims to compare the influence of chemical nature and structure of different ligands of nitroso-ruthenium complexes on the cytotoxic potential for human cell line 239FT.

\section{Methods}

Because of collaboration with the Nikolaev Institute of Inorganic Chemistry SB RAS, we have great opportunity to select compounds with certain ligands to adjust the necessary properties: cytotoxicity and solubility in water. We measured the cytotoxicity potential of novel nitrosyl complexes with different ligands on a cancer cell line by MTT analysis.

\section{Results}

For ruthenium nitroso complexes, an increase in cytotoxicity was shown in the series: water-soluble $\mathrm{NH}_{3}-$ containing complexes $\left(\mathrm{IC}_{50}>0,9 \mathrm{mM}\right), \mathrm{NO}_{2}$-containing complexes, chlorine-containing complexes $\left(\mathrm{IC}_{50}<20 \mu \mathrm{M}\right)$. Among chlorine-containing complexes, the complex $\left[\mathrm{Ru}(\mathrm{NO})\left(\mathrm{C}_{8} \mathrm{H}_{9} \mathrm{NO}_{2}\right)_{2} \mathrm{Cl}_{3}\right]$ exerted the highest cytotoxicity $\left(\mathrm{IC}_{50}=1,5 \pm 0,4 \mu \mathrm{M}\right)$. The shift of the ester moiety in the pyridine ligand from the fourth to the third position decreased cytotoxicity by a factor of five $\left(\mathrm{IC}_{50}=7,8 \pm 0,8 \mu \mathrm{M}\right)$, and the replacement of the ethyl substituent in the ester moiety with methyl one, decreased cytotoxicity by a factor of two.

\section{ACKNOWLEDGMENT}

This work was partially supported by Russian State funded budget project \# AAAA-A17-117020210023-1 to ICBFM SB RAS.

\section{REFERENCES}

[1] Mikhailov A. A., Khantakova D. V., Nichiporenko V. A., Glebov E. M., Grivin V. P., Plyusnin V. F., Yanshole V. V., Petrova D. V., Kostin G. A., Grin I. R. (2019) Photoinduced inhibition of DNA repair enzymes and the possible mechanism of photochemical transformations of the ruthenium nitrosyl complex [RuNO(bPic)2(NO2)2OH]. Metallomics, 11 (12): 1999-2009.

[2] Kostin G.A., Mikhailov A.A., Kuratieva N.V., Pischur D.P., Zharkov D.O., Grin I.R. (2017) Influence of pyridine-like ligands on the structure, photochemical and biological properties of nitro-nitrosyl ruthenium complexes. New J. Chem., 41: 7758-7765. 